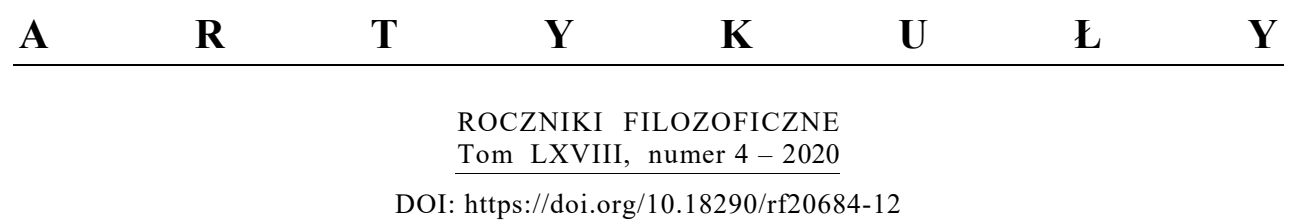

ZHIQIANG SUN \& FENRONG LIU

\title{
THE INFERENCE PATTERN MOU IN MOHIST LOGIC - A MONOTONICITY REASONING VIEW
}

\section{INTRODUCTION}

(a) A white horse is a horse. To ride a white horse is to ride horses. ${ }^{1}$

(b) Her younger brother is a handsome man. Loving her younger brother is not loving handsome men.

These passages are taken from the Xiaoqu chapter of the Mohist Canons. The Canons are a collection of writings by anonymous members of the Mohist school, compiled probably between the late 4 th and mid- $3^{\text {rd }}$ century B.C. This text is particularly interesting for its special attention to logic, language, and argumentation. The hope is that by understanding it properly, we will gain insight into the way in which people thought in ancient times.

According to the Mohists, the above examples illustrate an inference pattern called mou 佉, which the noted sinologist A.C. Graham translates as "parallelizing." Mou is explicitly defined in the Canons as "comparing propositions and letting all "proceed'." The definition is qualified by the admission that "mou is valid only as far as it reaches." As an inference pattern it is therefore not considered universally valid.

ZHIQIANG SUn (ORCID: https://orcid.org/0000-0002-3815-8888) \& Prof. FENRONG LIU (ORCID: https://orcid.org/0000-0001-7931-0324), Tsinghua University (Chin. 清华大学 [Qīnghuá Dàxué]), Department of Philosophy; address for correspondence: Department of Philosophy, Tsinghua University, 100084 Beijing, China; e-mail: fenrong@tsinghua.edu.cn.

${ }^{1}$ The primary reference of our translations is Graham (1978). We will give an indication whenever major revisions or corrections are made.

${ }^{2}$ Wu 2006, 628: 侔也者, 比辭而俱行也. Tr. GraHAM 1978, 483.

${ }^{3}$ Wu 2006, 628: 侔也者, 有所至而正. Tr. GRAHAM 1978, 483. 
The text distinguishes the two cases:

(a) has a positive conclusion, and is labelled shi er ran 是而然.We take the text as presenting this as a valid inference pattern. ${ }^{4}$ Put it formally, "N1 is N2. VN1 is VN2," where N1 and N2 are nouns, V is a transitive verb;

(b) has, by contrast, a negative conclusion, and is labelled shi er buran 是而不然, with the form “N1 is N2. VN1 is not VN2."

In this paper, we will make use of the local context where these examples occur and provide new reasons for explaining why shi er ran examples are valid and shi er buran is giving us counter-examples. Before going further, let us first quickly review a representative sample of approaches to the interpretation of these texts. For a detailed survey, we refer to Sun (2020).

Chen (1983) emphasized the meaning of the added verb in the inference. The meaning of 'riding' in (a) is the same in both occurrences, and this explains why the inference is valid. In (b), "loving her brother" refers to love between family members, and "loving handsome man" refers to love between partners. The difference in meaning undermines the validity of the inference. ZHANG (1998) stressed the vital role of the quantifiers in mou reasoning. Taking $S, P$, and $M$ as unary predicates for "is a white horse," "is a horse," and "is a man," respectively, $R$ a binary predicate for "riding," he formalized the above example (a) in predicate logic as $\forall x(S x \rightarrow P x) / \forall x((M x \rightarrow \exists y(S y \wedge R x y)) \rightarrow(M x \rightarrow \exists y(P y \wedge R x y)))$ and showed its validity. Lucas (2010) used set theory, reconstructing the inference as $W \subseteq H / W \cap R \subseteq H \cap R$, where $W$ stands for the set of white horse, $H$ stands for the set of horses, $R$ stands for the set of animals that are ridden. For shi er buran, Lucas' explanation is similar to Chen's. He says that there is a difference between the meaning of "loving" in (b): "one in the family sense and one in the social sense". Liu and Zhang (2010) introduced considerations of monotonicity. A typical example of upward monotonicity inference is the following: if some horses ran, some animals ran. Here the denotation of the predicate "animal" is an extension of that of "horses." The existential quantifier in the statement "some horses ran" creates an "upward-entailing" environment for the predicate "horses." In Aristotle's terms, such inferential contexts allow us to move up from a species to a larger genus. Liu and Zhang employed this approach to analyze example (a), arguing that we have good reasons to infer from "riding a (some) white horse" to "riding a (some) horse".

We will follow the approach of Liu and Zhang (2010) but extend it to examine the Mohists' examples more systematically. We will look at the

\footnotetext{
${ }^{4}$ Note that we are using validity here, but it is debatable whether this is a concept that was available to the people of ancient China. See also FraSER 2012.
} 
complete set of examples from the Xiaoqu, with particular consideration of the arrangement of those examples in the original text, examining both logical and linguistic aspects. Finally, we will consider examples that involve multiple quantifiers at different positions, the interaction of these quantifiers, and its influence on reasoning with monotonicity. Overall, we aim to deliver a uniform explanation of why shi er ran examples are valid and why shi er buran examples are counter-examples to the validity of the pattern.

The rest of the paper is structured as follows. In Section 2, we present a complete list of examples from the Mohist text. Section 3 is a quick introduction to the theory of monotonicity, the main background that we rely on to carry out our analysis. Section 4 is a more detailed study. We consider not only logical aspects of the examples but also relevant features of classical Chinese. In Section 5 we divide the examples of shi er buran into three groups and explain what goes wrong. Finally, we conclude briefly in Section 6 .

\section{A COMPLETE LIST OF EXAMPLES}

To prepare our discussion, we present the complete list of examples from the Xiaoqu. These examples are arranged in the same order as in the original text. It will become apparent that the arrangement is crucial for a proper understanding of their logical relevance. The first set, (1) a-d, are examples of shi er ran and the second set, (2) a-k, are examples of shi er buran.

(1) shi er ran:

a. A white horse is a horse. To ride a white horse is to ride horses.

b. A black horse is a horse. To ride a black horse is to ride horses.

c. A female slave is a person. To love a female slave is to love people. ${ }^{5}$

d. A male slave is a person. To love a male slave is to love people. ${ }^{6}$

(2) shi er buran:

a. A female slave' s parents are people.

A female slave serving her parents is not serving people. ${ }^{7}$

\footnotetext{
${ }^{5}$ Graham $(1978,485)$ translates this as "Jill is a person. To love Jill is to love people." Here "Jill" is “獲” which Graham takes to be a personal name. Instead, we follow Bi Yuan in taking this to refer to slaves, specifically female slaves. See Wu 2006, 636.

${ }^{6}$ Graham $(1978,485)$ translates this as "Jack is a person. To love Jack is to love people." Here “Jack” is Graham's translation of the word “臟” that Bi Yuan takes to mean “male slaves."

${ }^{7}$ Again, our translation departs from Graham's because of the disagreement about whether the text contains personal names or common nouns.
} 
b. Her younger brother is a handsome man.

Loving her younger brother is not loving handsome men.

c. A carriage is a wooden product.

Riding carriage is not riding a wooden product.

d. A boat is a wooden product.

Riding a boat is not riding a wooden product. ${ }^{8}$

e. Robbers are people.

Increasing robbers is not increasing people. ${ }^{9}$

f. (Robbers are people). ${ }^{10}$

Being without robbers is not being without people.

g. (Robbers are people).

To dislike increasing robbers is not to dislike increasing people.

h. (Robbers are people).

Desiring to be without robbers is not desiring to be without people.

i. Robbers are people.

Loving robbers is not loving people.

j. (Robbers are people).

To dislike robbers is not to dislike people. ${ }^{11}$

k. (Robbers are people).

Killing robbers is not killing people.

As mentioned before, (1) a-d have the same form "N1 is $\mathrm{N} 2 . \mathrm{VN} 1$ is VN2" while (2) a-k share the form "N1 is N2. VN1 is not VN2".

Later, we will analyze these examples step by step, to seek an answer to the following question: what kind of inference rule justifies the shi er ran pattern? Put differently, what are the rules that make the inference of " $\mathrm{N} 1$ is N2. VN1 is VN2" valid? As a theoretical foundation for this study, we'll first review the concept of monotonicity.

\footnotetext{
${ }^{8}$ Graham $(1978,487)$ translates this passage as "A boat is wood. But entering a boat is not entering wood". Our translation is based on a different emendation of the text. We will return to this point in Section 4.

${ }^{9}$ In (2) e-g, the crucial notion is duo 多 (many). Graham $(1978,487)$ has this as "Robbers are people, but abounding in robbers is not abounding in people, being without robbers is not being without people." Duo was used to describe some quantitative aspects of robbers or people. We follow Wu Yujiang's emendation, interpreting duo as a verb, meaning "make ... more," or "increase..." Similarly, wu in (2) f is a verb too, which means "be without."

10 "Robbers are people" in (2) $\mathrm{f}$-h is omitted in the original text.

${ }^{11}$ Graham translates this passage as "(Robbers are people). But 'not loving robbers' is not 'not loving people". We have treated the negation as part of the verb, to make it conform to the other passages.
} 


\section{MONOTONICITY : THE BASICS}

Monotonicity is one of the most fundamental properties that many valid inferences depend on. Both linguists and logicians have studied reasoning with monotone quantifiers, see, e.g., Suppes (1979), van Benthem (1986, 1991), Westerståhl (2006, 2012) and Moss (2010). In what follows, we introduce four cases. To do this, we will need to make the two quantifiers in subject and object position explicit. Later, this will be justified in the context of classical Chinese.

Left-downward monotonic $\left(\downarrow M O N_{R}\right)$ : if $\mathrm{Q}_{1} \mathrm{~S} \vee \mathrm{Q}_{2} \mathrm{P}$ and $\mathrm{S}^{\prime} \subseteq \mathrm{S}$, then $\mathrm{Q}_{1} \mathrm{~S}^{\prime} \mathrm{V} \mathrm{Q}_{2} \mathrm{P}$.

Here $\mathrm{V}$ ranges over transitive verbs. ${ }^{12}$ The inference $\downarrow M O N_{R}$ is valid when $\mathrm{Q}_{1}$ is a universal quantifier, either positive all or negative none. For example, "if all archeologists study some sculptures, then all male archeologists study some sculptures."

Left-upward monotonic $\left(\uparrow M O N_{R}\right)$ : if $\mathrm{Q}_{1} \mathrm{~S} \vee \mathrm{Q}_{2} \mathrm{P}$ and $\mathrm{S} \subseteq \mathrm{S}^{\prime}$, then $\mathrm{Q}_{1} \mathrm{~S}^{\prime} \mathrm{V} \mathrm{Q}_{2} \mathrm{P}$.

The inference $\uparrow M O N_{R}$ is valid when $\mathrm{Q}_{1}$ is the existential quantifier some. For example, "if some male archeologists study some sculptures, then some archeologists study some sculptures."

Compared with left monotonicity, the conditions for right monotonic reasoning to be valid are more complicated. When Suppes (1979) extended Aristotle's syllogistic with verb phrases, he observed that a distinction must be made between positive and negative quantifiers in subject position. $\mathrm{He}$ noticed that both positive quantifiers all and some act the same way, in the sense of providing constant context with the same semantical impact on varying terms in the verb phrase.

Right-upward monotonic $\left(M O N_{R} \uparrow\right)$ : if $\mathrm{Q}_{1} \mathrm{~S} \vee \mathrm{Q}_{2} \mathrm{P}$ and $\mathrm{P} \subseteq \mathrm{P}^{\prime}$, then $\mathrm{Q}_{1} \mathrm{~S} \vee \mathrm{Q}_{2} \mathrm{P}^{\prime}$.

The inference $M O N_{R} \uparrow$ is valid either

(1) when the subject quantifier $\mathrm{Q}_{1}$ is a positive quantifier and the object quantifier $\mathrm{Q}_{2}$ is some or not all, for example, "if all boys eat some apples, then all boys eat some fruit" and "if some boys do not eat all apples, then some boys do not eat all fruit", or

\footnotetext{
${ }^{12}$ The logic of transitive verbs is considered in Suppes (1979) and Moss (2010).
} 
(2) when the subject quantifier $\mathrm{Q}_{1}$ is a negative quantifier, say, none, and object quantifier $\mathrm{Q}_{2}$ is all, for example, "if no one read all novels, then no one read all books." 13

So, the effect of a negative quantifier in subject position is to reverse the direction of monotonicity. The positive quantifier all normally allows for downward monotonic inferences, but when the subject quantifier is negative, the pattern switches to upward monotonic. With a positive subject quantifier, it stays downward.

Right-downward monotonic $\left(M O N_{R} \downarrow\right)$ : if $\mathrm{Q}_{1} \mathrm{~S} \vee \mathrm{Q}_{2} \mathrm{P}^{\prime}$ and $\mathrm{P} \subseteq \mathrm{P}^{\prime}$, then $\mathrm{Q}_{1} \mathrm{~S} \vee \mathrm{Q}_{2} \mathrm{P}$.

The inference $M O N_{R} \downarrow$ is valid either

(1) when the subject quantifier $\mathrm{Q}_{1}$ is positive and the object quantifier $\mathrm{Q}_{2}$ is all or none, for example, "if every boy eats all fruits, then every boy eats all apples" and "if every boy does not eat any fruit, then every boy does not eat any apples", or

(2) when the subject quantifier $\mathrm{Q}_{1}$ is negative, say, none, and the object quantifier $\mathrm{Q}_{2}$ is some, for example, "if no one reads some novels, then no one reads some books." 14

This ends our quick introduction. In the next section, we will analyze the examples from the Mohist text using these rules. We will argue that the Mohists observed monotonicity patterns in reasoning, and that this is the principle that distinguishes shi er ran from shi er buran.

\section{MONOTONIC REASONING \\ AND THE VALIDITY OF SHI ER RAN}

First we consider the positive cases, which the Mohists labelled as shi er ran. We will formalize each of them, and considers which monotonicity principles apply.

\subsection{FormaLIZING THE EXAMPLES AND QUANTIFICATION ISSUES}

A striking feature of the examples in the text is use of verb-object expressions. The sentence structure is more complicated than it looks. Take (1) a as an example,

\footnotetext{
${ }^{13}$ In the sentence "no one can read all books", the scope of the universal quantifier is narrow. In predicate logic: $\neg \exists x(\operatorname{man}(x) \& \forall y(\operatorname{book}(y) \rightarrow \operatorname{read}(x, y)))$.

${ }^{14}$ Similarly, the scope of the existential quantifier some here is narrow.
} 
(1) a. Bai ma, ma ye. 白馬, 馬也.

A white horse is a horse.

Cheng bai ma, cheng ma ye. 乘白馬, 乘馬也.

To ride a white horse is to ride horses.

The first part has the form "A, B ye," which is a typical form of predication in classical Chinese, meaning that $\mathrm{A}$ is $\mathrm{B}$. In the second part, a verb cheng (乘, ride) is added to the previous two noun phrases, forming verb-object expressions: "cheng bai ma" and "cheng ma." These can also be seen as incomplete sentences, with a missing subject. As suggested by Graham's translation of mou, these passages contain two expressions arranged in parallel. Our question is then whether we can infer the second from the first? We interpret shi er ran as answering this question positively: the inference is valid. So we have the following argument:

A white horse is a horse

$\mathrm{X}$ rides a white horse

$\therefore \mathrm{X}$ rides horses

Here the X stands for the missing subject. In some of the other examples, this subject is provided explicitly. The argument has the form of a relational syllogism of Moss (2010) with "S is $\mathrm{P}$ " and "X V S" as the premises and "X V P" as the conclusion. But to complete this analysis, we need to specify the implicit quantifiers in both the subject and predicate:

All white horses are horses

Some/all X rides some/all white horses

$\therefore$ Some/all $\mathrm{X}$ rides some/all horses

In the Chinese of the period, there is no explicit marking for singular and plural and object nouns are not modified by determiners. The phrase "cheng bai ma" could mean "rides the white horse", "rides a white horse", "rides some white horses" or "rides all white horses". And there are more possibilities for the missing subject $\mathrm{X}$.

One interesting issue arises: how did classical Chinese deal with quantification? The Mohists discussed two quantifiers explicitly: the existential you (有 some) and the universal zhou (周 all).

'He loves people' requires him to love all people without exception, only then is he deemed to love people. 'He does not love people' does not require that he loves no people at all; he does not love all without exception, and by this criterion, is deemed not to love people.... 
'He rides horses' does not require him to ride all horses without exception before being deemed to ride horses; he rides some horses, and by this criterion is deemed to ride horses. ...

These are cases in which something 'applies without exception in one case but not in the other. ${ }^{15}$

Here the Mohists take the expression “cheng $m a$ 乘馬 (ride horse)” to be their primary example of a phrase to give the existential reading "you cheng $y u m a$ 有乘於馬," literally, there are some horses for riding. Likewise, the expression “ai ren 愛人 (love person)" is taken to be the main example of a phrase to be understood universally, “zhou ai ren 周愛人," literally, in all cases love people. ${ }^{16}$ The final quoted phrase is a translation of "yi zhou er yi buzhou一周而一不周," which word-by-word is “one all but one not all" and is presented here as a summary of the discussion.

So, although classical Chinese syntax does not tell us how to read the quantification pattern in the Mohist examples, their use of these stock examples does.

\subsection{EXAMPLEs (1) A-D REVISITED}

With "cheng ma" disambiguated, we can specify the logic of (1) a:

(1) $a^{\prime}$. All white horses are horses

Some/all X ride some white horses

$\therefore$ Some/all $\mathrm{X}$ ride some horses

With the choice of universal or existential in the premise repeated in the conclusion. This is exactly the principle $M O N_{R} \uparrow$ of right upward monotonicity, when the subject quantifier is positive. Likewise, for (1) b we get:

(1) $b^{\prime}$. All black horses are horses

Some/all X ride some black horses

$\therefore$ Some/all $\mathrm{X}$ ride some horses

The repetition of the pattern with black and white emphasizes that it is the form of the passage that is being considered, but also, that the particular word can be relevant. And this creates a problem for our analysis of (1) c and d. If we are to take these as examples of valid inferences, as the designation shi

\footnotetext{
${ }^{15} \mathrm{Wu} 2006 ， 630$ : 愛人, 待周愛人而後為愛 人.......乘馬, 不待周乘馬然後 為乘 馬也; 有乘於馬，因為乘馬矣。…..此一周而一不周者也。Translation GRAHAM 1978, 491.

${ }^{16}$ More precisely, zhou corresponds to the universal quantifier of traditional rather than modern logic. Unlike $\forall$, zhou has existential import. For more discussion of the logical impact of this distinction, see WESTERSTÅHL 2012.
} 
er ran suggests, our interpretation should conform to $M O N_{R} \uparrow$, namely,

(1) $c^{\prime}$. All female slaves are people

Some/all X loves some female slaves

$\therefore$ Some/all X loves some people

But on our understanding of the Mohists' use of stock examples, "ai ren (love person)" should be taken to mean "loves all people." And this would result in an invalid inference pattern.

In this case, however, there is sufficient context to override the stock interpretation of "ai ren." The passages are grouped together with two other passages in a way that clearly indicates their parallel structure. And they are placed after the pattern has been established using "cheng $m a$ " to indicate an existential reading. And this is emphasized by including the (otherwise redundant) example of black horses as well as white horses. Finally, the passages are collectively marked positively as shi er ran, and this would be hard to explain with the stock quantification reading of "ai ren".

\section{SHI ER BU RAN: WHEN MONOTONICITY FAILS}

The Xiaoqu has eleven examples marked as shi er buran. Each of these, (2)a-k have the grammatical structure "N1 is N2. VN1 is not VN2." Although similar to the shi er ran cases, we cannot interpret these as valid inferences to a negative conclusion, but rather as counter-examples. The denial $(f e i)$ of the second statement shows that one cannot draw a positive conclusion.

Looking at (2) a and b, we see that the topic is people. (2) a is about "shi ren 事人 (serve person)" and (2) b is about "ai ren" again. Taking the stock interpretation of "ai ren" as indicating the universal quantifier, we can specify the logic of the arguments as follows:

(2) $a^{\prime}$. All parents of female slaves are people

Some/all female slave serves all their parents

$\therefore$ Some/all female slave serves all people

(But this is not the case.)

$\mathrm{b}^{\prime}$. All her younger brothers are handsome men

Some/all X loves all her younger brothers

$\therefore$ Some/all $\mathrm{X}$ loves all handsome men

(But this is not the case.)

These are patterns in which monotonicity reasoning fails. They are 
invalid. Specifically, the rule $M O N_{R} \downarrow$ tells us that the inference should be downward in this case, not upward. And so this accords with our interpretation of shi er buran as indicated a failed inference.

The next two passages use the verb "cheng (ride)" but instead of taking this with its stock existential meaning, we conform to our policy in (1) of allowing the initial examples to establish the pattern of quantification. Thus we have

(2) $c^{\prime}$. All carriages are wooden products

Some/all $\mathrm{X}$ rides all carriages

$\therefore$ Some/all $\mathrm{X}$ rides all wooden products

(But this is not the case.)

$d^{\prime}$. All boats are wooden products

Some/all X rides all boats

$\therefore$ Some/all $\mathrm{X}$ rides all wooden products

(But this is not the case.)

These are again examples of invalid inferences. It is $M O N_{R} \downarrow$ which applies to the quantificational context of the second premise, and so only downward monotone inferences are possible.

It should be noted that our interpretation of (2) $d$ is controversial. In early editions of the text, such as that of the eighteenth century scholar Bi Yuan, the verb-object phrase in (2) d is "ren quan 人船 (people boat)." See BI $(2002,745)$. Clearly this makes no sense but there has been disagreement about how to fix it. Sun Yirang, a well-known scholar in late Qing Dynasty, quoted an earlier commentator's note that "ren 人" should be emended to " $r u$ 入" which means "enter", hence the translation "entering boats" and "not entering wood", which has been accepted by most scholars, e.g. Yu (1984), Sun (1987) and Liu and Zhang (2010). The passage is then explained by observing that "enter wood" is a euphemism for "dying." Instead, we follow the text of $\mathrm{Wu}$ (2006) who provides extensive evidence for correcting "ren 人” to "cheng 乘" and so restoring the theme of riding to this pair of passages.

Next, we consider (2) e. But before giving our analysis, another problematic words needs to be considered. Scholars of the Mozi text have very different interpretations of the word "duo 多 (many)". Yu (1986) takes duo to be a quantifier that describes the quantity of robbers and people, "many robbers" and "many people." Graham (1978) takes duoren 多人 to be an abstract noun "the abundance of people." Lucas (2010) continues with Graham's interpretation and emphasized that 'abounding in robber' for duo- 
dao 多盗 expresses a characteristic of the class of robbers and not of individual robbers. Liu and Zhang (2010) take duo to be an indefinite quantifier whose interpretation depends on some standard supplied by its matching predicate. Because of the relative number of robbers and people, the numbers implied by "many robbers" and "many people" are quite different.

While these various interpretations can be justified individually, and recognizing the difficulties in establishing evidence for any one, we argue that the best interpretation of $d u o$ in these passages is as a verb, "to increase." In classical Chinese, a single word typically has a number of grammatical categories. So it is not at all strange for $d u o$ to be used as a verb, adverb, adjective or even a noun. Moreover, its meaning as the transitive verb "to increase" is well testified in the literature of the time. ${ }^{17}$ But in the specific context of the Xiaoqu examples we have been considering, the main reason to take $d u o$ as a verb is grammatical parallelism. In all of the shi er ran examples, we have the pattern "N1 is $\mathrm{N} 2 . \mathrm{VN} 1$ is VN2" and in almost all of the shi er bu ran examples we have "N1 is N2. VN1 is not VN2."18

With this interpretation of " $d u o$ " we can give our final interpretation:

(2) $e^{\prime}$. All robbers are people

Some/all X increases (the number of) all robbers

$\therefore$ Some/all $\mathrm{X}$ increases (the number of) all people

(But this is not the case.)

The reason for the failure of (2) $\mathrm{e}^{\prime}$ is slightly different from the previous examples. Although some ways of increasing the number of robbers would increase the number of people, by breading new robbers, perhaps, there are also (less unusual) ways of increasing the number of robbers without increasing the number of people, such as by turning some non-robbers to a life of crime. For more on this, see van Benthem and Liu (2020).

\footnotetext{
${ }^{17}$ For example, in Xunzi, we find “因物而多之, 孰與聘能而化之,” “To follow along with things and increase them-How can this compare to developing their powers and transforming them?” See WANG 2013, 375, translation Hutton 2014, 180. And in Guoyu, “為遊士八十人，奉之 以車馬、衣表, 多其資幣, 使周遊於四方, 以號召天下之賢士, “ “Please select eighty lobbyists who are good at diplomacy, and grant them with horses, chariots, and clothing, increase their wealth, and let them travel around the world to invite the wise men." See XU 2002, 229-230, authors' translation.

${ }^{18}$ Examples (2) $\mathrm{g}$ and $\mathrm{h}$ are not considered here, but they are not so relevant to this point because they are instances of yuan 援 (adducing) rather than mou.
} 


\section{CONCLUSION AND FUTURE WORK}

We have proposed a new systematic study of the Mohist inference pattern mou from the perspective of monotonic reasoning, using insights from both logic and linguistics. We emphasized specific features of classical Chinese, and the organizing of context of these passages to give our interpretation. In particular, we have argued for the following conclusions.

The inference form "N1 is N2. VN1 is VN2." is not universally valid. The reason why examples (1) a to d of shi er ran are valid is that the monotonicity rule $M O N_{R} \uparrow$ can apply to the quantifier in object position. In other words, if an example of shi er ran is valid, it has to be right upward monotonic reasoning with the form:

$$
\frac{\text { all } P \text { are } P^{\prime}, \text { some / all } S V \text { some } P}{\text { some / all } S V \text { some } P^{\prime}} .
$$

Regarding the shi er buran examples, the monotonicity rule can also provide a clear answer to why the inferences fail. The universal quantifier for the object of the transitive verb licenses only downward monotonic inferences, and upward inferences are invalid.

For future research, there are fascinating examples in the Canons that we have not yet touched. Closely related to the examples considered here are those marked bushi er ran 不是而然. These have the form “N1 is not N2. VN1 is VN2." And in addition to mou, the Mohists considered other inference patterns: yuan 援, pi 辟 and tui 推. They are of great interest to us. Once we have a good understanding of the text and the reasoning patterns it contains, we would like to compare them to similar forms in the western tradition.

Finally, in this paper, we have adopted the theory of monotonicity from SuPPES (1979). However, we are aware of other approaches, such as the monotonicity calculus proposed by VAN BENTHEM (1986). We plan to extend our analysis with those tools.

\section{ACKNOWLEDGEMENT}

We thank Piotr Kulicki for providing the opportunity for sharing our ideas. We thank two anonymous reviewers for their very useful comments. We thank Johan van Benthem and Jeremy Seligman for their extensive comments. 


\section{BIBLIOGRAPHY}

VAN BENTHEM, Johan. 1986. Essays in Logical Semantics. Springer Netherlands.

van Benthem, Johan. 1991. Language in Action: Categories, Lambdas, and Dynamic Logic. North Holland.

van Benthem, Johan, and Fenrong Liu. 2020. "New Logical Perspectives on Monotonicity." In Proceeding of the Second Tsinghua Interdisciplinary Workshop on Logic, Language, and Meaning: Monotonicity in Logic and Language. To appear.

Bı, Yuan. 2002. Mozi (Japanese edition). In Mozi Daquan. Vol. 11, edited by Ren Jiyu, 449-896. Beijing: Beijing Library Press.

Chen, Menglin.1983. Mobian Luojixue. Jinan: Qilu Press.

Fraser, Chris. 2012. "Truth in Moism." Journal of Chinese Philosophy, 39: 351-368. doi: 10.1111/j.1540-6253.2012.01727.x

Graham, A.C. 1978. Later Mohist Logic, Ethics and Science. Hong Kong: The Chinese University Press.

Hutton, Eric L. 2014. Xunzi: The Complete Text. Princeton: Princeton University Press.

Liu, Fenrong, and Jialong Zhang. 2010. "New Perspectives on Moist Logic." Journal of Chinese Philosophy 37 (4): 605-621.

LuCAS, Thoerry. 2010. "The Logic of Mohist Reasonings; Leis and Structured Sorts." Monthly Review of Philosophy and Culture 37 (8): 65-93.

Moss, Lawrence S. 2010. "Natural Logic and Semantics." In Logic, Language and Meaning. Lecture Notes in Computer Science. Vol. 6042, edited by Maria Aloni, Harald Bastiaanse, Tikitu de Jager, and Katrin Schulz, 84-93. Berlin, Heidelberg: Springer.

Sun, Zhongyuan. 1987. The History of Chinese Logic (Pre-Qin Volume). Beijing: China Renmin University Press.

Sun, Yirang. 2001. Mozi Jiangu. Beijing: Zhonghua Book Company.

Sun, Zhiqiang. 2020 (to appear). "A Survey on the Logical Study of Mou." In Handbook of the History of Logical Thought in China, edited by Fenrong Liu, Jeremy M. Seligman, and Jincheng Zhai. Berlin, Heidelberg: Springer.

SuPPES, Patrick. 1979. "Logical Inference in English: A Preliminary Analysis." Studia Logica 38 (4): 375-391.

WANG, Xianqian. 2013. Xunzi Jijie. Beijing: Zhonghua Book Company.

Westerståhl, Dag, and Stanley Peter. 2006. Quantifiers in language and logic. Oxford University Press.

WesterstÅHL, Dag. 2012. "Classical vs. Modern Squares of Proposition, and Beyond." In The Square of Opposition: A General Framework for Cognition, edited by Jean-Yves Beziau and Gillman Payette, 195-229. Frankfurt am Main, Bern, Bruxelles, New York, Oxford, Warszawa, Wien: Peter Lang.

Wu, Yujiang. 2006. Mozi Jiaozhu. Beijing: Zhonghua Book Company.

Xu, Yuangao. 2002. Guoyu Jijie. Beijing: Zhonghua Book Company.

Yu, Jin. 1984. "The Inference of 'Mou' in the Mohist Canons." Journal of Teaching and Learning, (04): 83-87.

Yu, Jin. 1986. “On the Inference of 'Mou'." Journal of Nanjing Normal University (Social Science Edition), (02): 50-55. 
Yu, Yue. 2010. Mozi Pingyi. (Chunzaitang quanshu book series, vol. 2). Nanjing: Phoenix Books.

Zhang, Jialong. 1998. "On the Validity of 'Mou' in the Mohist Canons." In Selected Papers from Workshops on Chinese Mingbianxue and Methodology, on Taoism and the West, and on Feng Youlan's Philosophy, edited by Junquan Chen, 40-44. Beijing, Philosophical Research.

\section{THE INFERENCE PATTERN MOU IN MOHIST LOGIC - A MONOTONICITY REASONING VIEW}

\section{Su m mary}

Taking the standpoint of monotonicity reasoning, this paper provides a systematic way of looking at the inference pattern mou in the Mohist text. We have taken a logical, as well as a linguistic perspective, emphasizing features of classical Chinese, the role of context, and making use of any possible clues that we can find from the old text. By applying monotonicity rules we provide a uniform account of why shi er ran examples are valid inferences, and shi er buran examples are counter-examples.

Keywords: Mohist logic; mou; monotonicity; contextual analysis.

\section{SCHEMAT WNIOSKOWANIA MOU W LOGICE MOHISTYCZNEJ}

$$
\text { Streszczenie }
$$

Biorąc za punkt wyjścia monotoniczność rozumowania, artykuł przedstawia systematyczny sposób interpretacji schematu wnioskowania mou w tekstach mohistycznych. Wzięliśmy pod uwagę zarówno perspektywę logiczną. jak i lingwistyczną, zwracając szczególną uwagę na specyfikę klasycznego języka chińskiego, rolę kontekstu i uwzględniając wszelkie możliwe wskazówki pochodzące ze źródłowych tekstów. Poprzez zastosowania reguł monotoniczności sformułowaliśmy jednolitą odpowiedź na pytanie, dlaczego shi er ran są uznawane za rozumowania poprawne, a shi er buran przeciwnie - uznawane są za kontrprzykłady.

Słowa kluczowe: logika mohistyczna, Mou, monotoniczność, analiza kontekstualna. 